\title{
Identification power line sections with increased electricity losses using sensors with Wi-Fi technology for data transmission
}

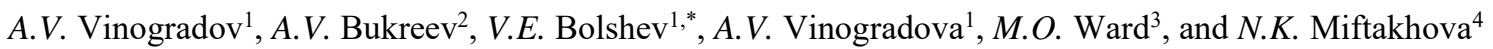 \\ ${ }^{1}$ Federal Scientific Agroengineering Center VIM, 5 1st Institutsky Proezd, Moscow, 109428, Russia \\ ${ }^{2}$ Orel State Agrarian University, 69 General Rodina St., Orel, 302019, Russia \\ ${ }^{3}$ Damascus University, Baramkah, Damascus, 30621, Syria \\ ${ }^{4}$ Kazan State Power Engineering University, 51 Krasnoselskaya St., Kazan, 420066, Russia
}

\begin{abstract}
The article presents portable timers-electricity meters (PTEM) which are devices for examining $0.4 \mathrm{kV}$ power lines. There are two developed several versions of the devices: single-phase PTEM used to examine single-phase branch lines to consumers, and three-phase PTEM used for any power line sections. Also, the method to identify sections of power lines with increased electricity losses by means of these devices is presented. The paper considers the application of the three-phase PTEM with Wi-Fi technology to transmit data. Up to six independent three-phase PTEMs with Wi-Fi technology can be installed at different points of the power transmission line and transmit measured data in real time to the central unit. The use of these devices allows determining both technological and commercial losses of electricity in different power line sections and draw conclusions about whether these losses are overestimated. On the basis of this, measures are taken to reduce losses.
\end{abstract}

\section{Introduction}

Identification of the sections of $0.4 \mathrm{kV}$ power transmission lines (PTL) with increased electricity losses is an urgent task. After solving this task electric grid companies can reallocate resources from the purchase of electric energy losses to reconstructing and modernizing electric networks. Significant forces of electric grid companies are aimed at identifying the sections with electricity losses, but nevertheless energy losses are still unreasonably high, especially commercial losses associated with unreasoned and non-contractual electricity consumption [1].

The peculiarity of this work is that it should be carried out mobilely without providing access to consumers' accounting devices at the first stage [2]. It should be possible to control electricity consumption in the power transmission lines and at the branch power lines to consumers, and compare data on consumption. In addition to the direct consumption of electric energy, it is rational to know the peak values of the consumed current and power, voltage changes at the measurement point. It will also make it possible to conduct a network survey, identify power line sections with insufficient transmission capability, deviations in power quality and reveal voltage unbalance in electrical network. In addition, it will be possible to verify the compliance of the power consumed by subscribers with the contractual conditions. It is desirable to organize all these measurements without disconnecting consumers and without attracting their special attention. There are existing devices that analyze the quality of electric energy and are able to control current and power in the network, for example, power quality analyzers. But they do not fully possess the necessary qualities as they are intended for several other purposes. They are also very expensive. Therefore, the purpose of this article is to develop technical means for organizing work to identify $0.4 \mathrm{kV}$ power line sections with increased electricity losses.

\section{Devices for examining $0.4 \mathrm{kV}$ power lines}

The device "portable timers-electricity meters " has been developed and allows performing the necessary functions of controlling the parameters of network operation modes and controlling electricity consumption. There are two versions of a device: single-phase (PTEM) [3] and three-phase (PTEM-3) [4]. These versions of the device have current and voltage sensors, but can operate only in a mode of current measurement when it is not possible to connect to voltage circuits. Taking into account the above tasks that a complex of technical means should identify energy losses, it should also allow autonomous continuous operation of the sensors and collecting measured data online by a unit for collecting and processing this data. Figure 1 shows the appearance of PTEM -3.

\footnotetext{
* Corresponding author: vadimbolshev@gmail.com
} 


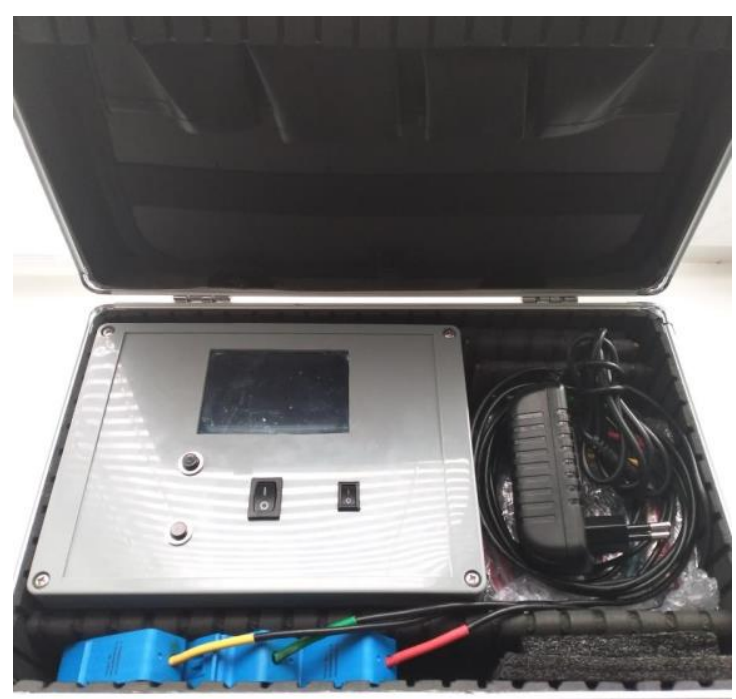

Fig. 1. The appearance of PTEM-3.

To identify power line sections with increased losses, it is necessary to install the simultaneous installation of several PTEM-3 devices at different sections of the power transmission line, to ensure their autonomous operation and then processing the received data [5]. Since the devices are synchronized in time, it is possible to carry out a comparison of these data and identify the sections where the energy losses are too high. It is also possible to analyze other modes of network operation modes such as a graph of the load, voltage, current and power consumption. Due to the fact that the data is written to a removable media, data processing does not require the device itself, that is, a new media can be installed and the device will continue to work at the same or a new control point of the network.

However, this version of the device does not provide the opportunity of online data transfer and, accordingly, the online analysis of information about power consumption modes and other network operation modes. This requires the ability to transfer data from devices using one of the c0mmunication technologies [6-9]. Therefore, the device was modernized in the following version - PTEM-3-W. This device contains current sensors with a current to voltage converter, voltage sensors, two mi-crocontrollers, TFT display, real-time clock unit, data recording unit, radio modules.

The central unit of the PTEM -3-W device (CU) is located either on the vehicle (4) or stationary, for example, on a $10 / 0.4 \mathrm{kV}$ transformer substation. PTEM 3-W sensors (3) which register electric power consumption and other parameters of the network operation mode are installed at network control points, for example, at a transformer substation (1), at branch lines to consumers (2) and at separate sections of power lines. Data from sensors via communication channels are transmitted to the PTEM-3-W central unit. Figure 2 shows the appearance of PTEM-3-W. A sensor of PTEM-3-W is presented on the left, and the central unit is on the right.

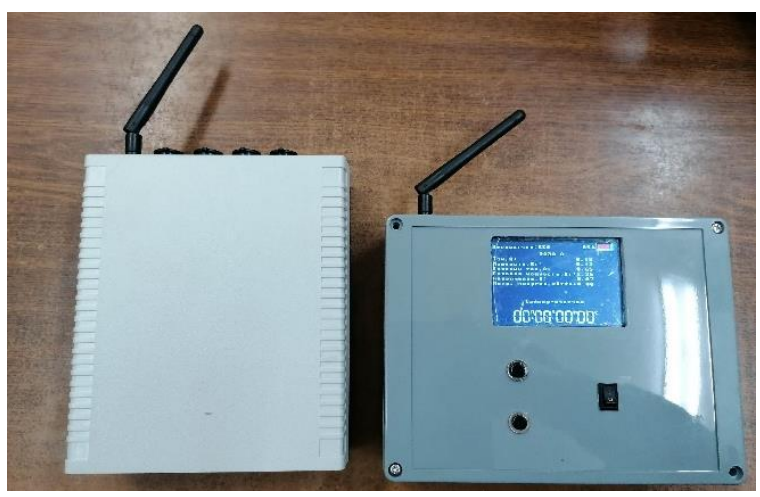

Fig. 2. Appearance of the sensor and the central unit of PTEM -3-W.

PTEM-3-W allows receiving data from sensors remotely via a Wi-Fi connection. Thanks to this, the device usage pattern is changing. The central unit of the device allows simultaneously working with six sensors that can be located at different points of an electrical network. These sensors transmit the measurement results to the central unit over the air. Figure 3 shows the utilization scheme of the device.

\section{Method to identify power line sections with increased electricity losses}

When using PTEM-3-W, the energy loss in the controlled power line section can be determined as the difference between the readings of the sensors and the readings of the consumers' metering devices.

For example, it is necessary to find out the loss of electricity in different power line sections shown in Figure 3. To that end, PTEM-3-W sensors will be set at the control points of the power transmission line and then the central unit will receive information from these sensors. The time of the control can be set from several minutes to several days or weeks. Also, if there is such an opportunity, it is rational to take readings from subscriber meters at the time of the beginning of measurements and at the time of their end. After receiving the data from the sensors, it will be processed. Technological losses in the section between PTEM -3-W 1 and PTEM -3-W 2 can be determined by equation (1):

$$
\Delta W_{1-2}=W_{1}-W_{2}-W_{3}
$$

where $W_{l}$ is the amount of electricity consumed for a given period of time according to the readings of the PTEM sensor $1 ; W_{2}$ is the amount of electricity consumed for a given period of time according to the readings of the PTEM 2 sensor; $W_{3}$ is the amount of electricity consumed for a given period of time according to the readings of the PTEM 3 sensor.

The actual total losses on the section can be calculated by equation (2) if the readings of the consumer's meter S1 is available:

$$
\Delta W_{1-2 f a c t}=W_{1}-W_{2}-W_{S 1},
$$




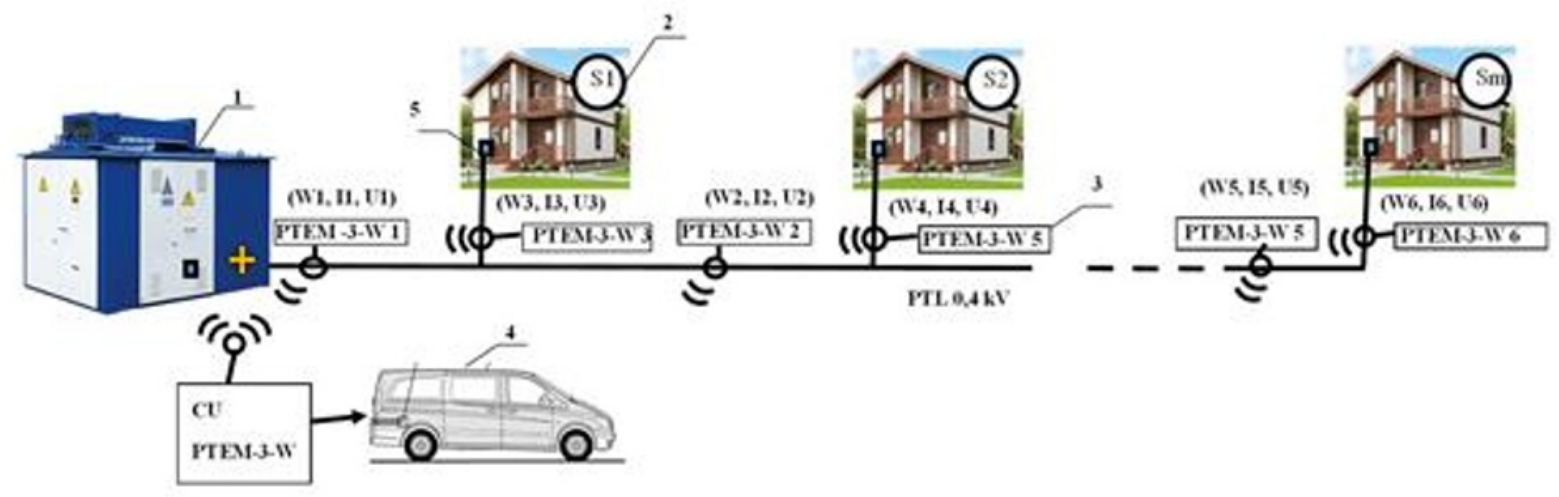

Fig. 3. PTEM -3-W utilization scheme to identify power line sections with high power losses.

where $W_{S 1}$ is the amount of electricity consumed for a given period of time according to the readings of consumer's meter S1.

Commercial losses can be calculated as follows (equation 3):

$$
\Delta W_{1-2 \text { com. }}=\Delta W_{1-2 \text { fact }}-\Delta W_{1-2},
$$

It should be should be taken into account that a small part of the technological losses will be included in the $\Delta W_{1-2 \mathrm{com}}$ losses, that is losses at the branch power line to consumer S1 (depending on the installation site of TEMP-3-W 3).

Similarly, it is possible to determine the losses in other sections of the power transmission lines. To identify sections with increased losses, it is necessary to understand what losses should be in these sections in the normal case which can be calculated by known methods $[10,11,12]$. Knowing the calculated values of technological losses in power line sections, they will be compared with the measured ones. Based on the received difference, a conclusion will be drawn on whether losses are overstated in this area or not. In any case, the calculated losses will differ from the measured ones since the calculation methods cannot sufficiently take into account all the parameters of power transmission lines (load changes constantly, voltage value at different sections is different and most often does not match the calculated value, etc.). However, the difference in the normal case will be negligible.

If there is a large difference between the measured and calculated losses, it is concluded that the losses in this section are overestimated and the reasons are analyzed.

Thus, it is possible to examine power transmission lines in terms of voltage losses on line sections, to construct a load graph for different sections, to determine peak values of current and power consumption and to estimate load and voltage unbalance. It allows verifying the adequacy of the transmission line capability, the power reserve of the transformer substation $10 / 0.4 \mathrm{kV}$, the compliance of the power quality with regulatory documents. Also, based on the measurement data, measures can be drawn up to modernize or reconstruct the examined power transmission lines.

\section{Conclusion}

As part of the study, the following results were obtained:

1. Technical means (portable timers-electricity meters in various versions) have been developed for examining $0.4 \mathrm{kV}$ power transmission lines and, in particular, for solving the problem to identify power line sections with increased electricity losses.

2. It is most rational to use the PTEM version equipped with Wi-Fi data transmission technology to identify electric power losses in $0.4 \mathrm{kV}$ power transmission lines since in this case several power transmission lines can be simultaneously monitored with the possibility of receiving information from sensors in real time.

3. The data obtained by PTEM allow calculating technological and commercial losses in the power transmission lines and draw conclusions about whether they are overestimated.

\section{References}

[1] A.V. Vinogradov, M.V. Borodin, Yu.A. Volchenkov, ZH.V. Peshehonova, Sovershenstvovanie deyatel'nosti po energosberezheniyu $i$ po osushchestvleniyu tekhnologicheskih prisoedinenij filiala OAO "MRSK CENTRA" - "ORYOLENERGO" [Improvement of energy saving and technological connections for the branch of ORELENERGO, a branch of IDGC of Center] (Publishing House of Orel State Agrarian University, Oryol, Russia, 2015)

[2] A.V. Vinogradov, A.V. Vinogradova, V.E. Bolshev, M.O. Ward, N.V. Makhiyanova, L. V. Dolomaniuk, Justification for creating a mobile complex to assess electric energy loss in power transformers during the operation process, E3S Web of $\quad 124$. DOI:10.1051/e3sconf/201912402009 (2019) 
[3] V.E. Bolshev, A.V. Vinogradov, A.V. Vinogradova, A.V. Bukreev, Tajmerelektroschyotchik mobil'nyj portativnyj [Portable timers-electricity meter], RF patent No. 191056 (2019)

[4] A.V. Bukreev, A.V. Vinogradov, Tajmerelektroschyotchik mobil'nyj portativnyj [Threephase portable timers-electricity meter], RF patent No. 195905 (2020)

[5] A. Vinogradov, V. Bolshev, A. Vinogradova, M. Borodin, A. Bukreev, I. Golikov, Mobile Measuring Complex for Conducting an Electric Network Survey (In Handbook of Research on Energy-Saving Technologies for Environmentally-Friendly Agricultural Development, Hershey, PA: IGI Global, 243267, 2020)

[6] M. Kuzlu, M. Pipattanasomporn, S. Rahman, Communication network requirements for major smart grid applications in HAN, NAN and WAN, Computer Networks 67, 74-88. DOI: 10.1016/j.comnet.2014.03.029 (2014)

[7] S.S.S.R. Depuru, L. Wang, V. Devabhaktuni, N. Gudi, Smart meters for power grid: challenges, issues, advantages and status, 2011 IEEE/PES Power Systems Conference and Exposition, 1-7. DOI: 10.1109/PSCE.2011.5772451 (2011)

[8] E. Ancillotti, R. Bruno, M. Conti, The role of communication systems in smart grids: architectures, technical solutions and research challenges, Communication Technologies 36, 1665-1697. DOI: 10.1016/j.comcom.2013.09.004 (2013)

[9] S. Galli, A. Scaglione, Z. Wang, For the grid and through the grid: The role of power line communications in the smart grid, Proceedings of the IEEE 99, 6, 998-927. DOI: 10.1109/JPROC.2011.2109670 (2011)

[10] W.G. YU, Y.J. XIONG, X.F. ZHOU, G.L. ZHAO, N. Chen, Analysis on technical line losses of power grids and countermeasures to reduce line losses [J], Power System Technology 18, 5457 (2006)

[11] E.I. Gracheva, O.V. Naumov, Estimation of power losses in electric devices of the electrotechnical complex, International Conference on Industrial Engineering, Applications and Manufacturing (ICIEAM), 1-6. DOI: 10.1109/ICIEAM.2019.8742923 (2019)

[12] M. Stojkov, K. Trupinic, S. Nikolovski, Technical losses in power distribution network, MELECON 2006-2006 IEEE Mediterranean Electrotechnical Conference, 1048-1051. DOI: 10.1109/MELCON.2006.1653279 (2006) 